\title{
Relationships of Resource Strategies, Family Composition, and Child Growth in Two Rural Timor-Leste Communities
}

\author{
Phoebe R. Spencer and Debra S. Judge *
}

Citation: Spencer, Phoebe R., and Debra S. Judge. 2021. Relationships of Resource Strategies, Family

Composition, and Child Growth in Two Rural Timor-Leste Communities. Social Sciences 10: 273. https:// doi.org/10.3390/socsci10070273

Academic Editors: Paula Sheppard and Kristin Snopkowski

Received: 19 April 2021

Accepted: 8 July 2021

Published: 16 July 2021

Publisher's Note: MDPI stays neutral with regard to jurisdictional claims in published maps and institutional affiliations.

Copyright: (c) 2021 by the authors. Licensee MDPI, Basel, Switzerland. This article is an open access article distributed under the terms and conditions of the Creative Commons Attribution (CC BY) license (https:// creativecommons.org/licenses/by/ $4.0 /)$.
School of Human Sciences, University of Western Australia, Perth, WA 6009, Australia; debra.judge@uwa.edu.au * Correspondence: phoebe.spencer@uwa.edu.au

\begin{abstract}
Subsistence and economic activities undertaken by households in the context of transition from subsistence farming to cash economies are sometimes seen as substitutable with only minimal reference to the households themselves. We use data from in-depth interviews of 190 householders in Ossu (mountains) and Natarbora (coastal plains), Timor-Leste, to query relationships of family composition, resource strategies, and their relationships to children's growth. Principal component analyses of six household composition variables reveal "grandparent and fostered-in children", "two generational households with numerous adults and children", and "smaller households with few adults and fostered-out children", explaining $72 \%$ of the variance. A similar procedure with 11 resource variables produced four components explaining $56 \%$ of resource variance. Households with grandparents have a pension income and engage in large animal husbandry, and are associated with better standardized BMI for resident children. Households with numerous members (but not grandparents) are more invested in subsistence gardening and are negatively associated with child stature. Salaried income is not associated with household composition, but children in these households are taller than their peers. Consistent differences between the two communities are partially a result of differences in socioecology, but there remain unexplained differences that may relate to cultural practices.
\end{abstract}

Keywords: anthropometrics; socioecology; subsistence farming; economic development; principal component analysis

\section{Introduction}

Human subsistence requires that time and energy be allocated among a suite of competing activities and opportunities. Traditional subsistence farming practice can be guided by culturally transmitted rules for the appropriate timing of and attention to various tasks. Over time, rules guiding successful practices persist and can be "adaptive" in the sense of decreasing risk and increasing energy acquisition. Environmental changes such as social disruption, economic development, or climate change disrupt historical experience, constrain some traditional options, and introduce others (Thu and Judge 2017). Longstanding rules are less likely guides to successful strategies. In rural Timor-Leste, it has proven difficult to find reliable independent predictors of children's growth (Judge et al. 2012; Spencer et al. 2017). Spencer et al. (2018b) associated correlated subsistence behaviors using Principal Component Analysis (PCA) and related household scores on the resulting independent components to child growth. There was modest success with this approach, but "community" was consistently a significant independent factor. Spencer et al. (2018b) considered sources of cash income and farming as two separate categories of resources and analyzed them separately. Here, we recognize the inherent trade-offs in time spent acquiring cash via daily work and farm production and look collectively at all resource strategies to determine those that are more or less integrated with each other. We then ask whether communities differ in their strategic sets and explore the relationships between family composition and resource strategies and whether/how these impact children's growth. 
Timor-Leste is one of the newest and least developed Asian countries. The country includes communities characterized by 16 Austronesian and Papuan language groups and varying systems of family affiliation. Independent since 2002, Timor-Leste has developed from a post-occupation, scorched earth position to a country dedicated to improving the conditions and potential for its 1.3 million population, approximately $70 \%$ of whom are rural. Eighty percent of the economically active population is engaged in subsistence agriculture (Macrotrends 2020). Within a large subsistence economy, households access cash income through participation in the nation's developing commercial economy (day labor, local marketing, and trading) or via state-sourced income, which includes pensions and jobs such as teaching and administration. Small pensions are available to the elderly and to impoverished mothers (the Bolsa da Mãe), and substantial pensions for veterans of Portuguese service and/or the fight for independence. The veteran's pension is highly valuable and provides higher income (but at longer intervals) than a government salary.

Timor-Leste's Human Development Index ranks 141 of 189 countries (United Nations Development Programme 2020). Although the life expectancy at birth has increased since 2002 to 69 years of age as infant mortality has declined, anthropometric indicators of child malnutrition have barely changed in spite of many health and nutrition initiatives by the Timor-Leste government and NGOs. The percentage of children under five years who are categorized as stunted hovers around the 50\% mark (Spencer et al. 2018b).

To better understand the local predictors of better or worse child growth, almost a decade of work in two rural communities has resulted in a longitudinal data set rich in anthropometrics and family ecology characteristics (Judge et al. 2012; Thu and Judge 2017; Spencer et al. 2018a). Ossu de Cima, a mountainous community of 4300 inhabitants in the central east, ranges from about $600 \mathrm{~m}$ ASL to $1000 \mathrm{~m}$ ASL and faces south from the country's central mountain range. The majority speak Makassae or Kairui as a first language (languages of Papuan origin). Natarbora/Barique is on the southern coastal plains with an altitude of 5-50 m ASL and a population of 5438 Tetun-terik speakers (Austronesian origin), 3000 of whom reside in the communities of our research. While most communities in Timor-Leste are patrilineal in family affiliation, somewhat less than $12.5 \%$ of the population are matrilineal (Narciso et al. 2012). In Ossu, family affiliation is through the male line, and generally, sons inherit the land-although land rights are often ambiguous or contentious in Timor-Leste as a result of dislocations during the occupation. Traditional marriage practice includes bride price (barlake) that until recently was counted primarily in water buffalo or cows (Bettencourt et al. 2013); more recently, other goodsincluding cash-have come into barlake negotiations. Children ostensibly belong to the father's lineage at the completion of payment of bride price. In contrast, Natarboran family affiliation is more matrilineal with strong bilineal practices. A ritual assignment of each child to either the mother's lineage or to the father's lineage is symbolic and, beyond the universal report that the first child is assigned to the mother's lineage, practices were described variously among Natarboran respondents. These assignments do not result in any change of location for the child but rather delineates their role in various ceremonies hosted by either the maternal or the paternal lineage.

Families are often characterized as groups of individuals with shared accommodation, resource streams, and relatedness through birth or marriage (Goody 1976). Family health and well-being are a product of the environment (e.g., resource availability, social stability, mortality risks), household decisions (Crooks et al. 2007), and social supports achievable during times of hardship or crisis (Hadley 2004). Child survival and growth are functions of the environment the family inhabits as well as the ways that resources and labor are allocated within the family (Chen et al. 1981; Harrison and Schmitt 1989). Our research has focused on child survival and growth as a function of conditions of the family within a local environment. Stem families (grandparent(s), parents, and children) are most common in Ossu, and while stem families predominate in Natarbora, joint families (two siblings and their spouses and children) are also common. In both communities, fostering of children is a common aspect of household composition. Households foster in children, usually 
those of relatives, or send children to live elsewhere (foster out). Fostering transfers vary in permanence; some children are essentially adopted into a new household, while others come and go between their biological household and their foster household or among fostering households. In neither community do foster children pay a growth penalty for not living with biological parents (Judge et al. 2012; Spencer et al. 2017).

The two rural communities in Timor-Leste vary in the agroecological zone and in traditional family affiliation but are both largely agricultural with basic similarities in agricultural participation and in child fostering practices. Children in Natarbora consistently show better growth than those in Ossu (Spencer et al. 2017). Natarbora children are also more physically active (Spencer et al. 2019). The question is whether the demonstrated differences in growth can be explained by the agroecological differences or whether there remains variation in growth that might be explained relative to community-level cultural variation, such as matrilineal and patrilineal affiliation systems.

In this paper, we look at how the communities differ in the organization of household economies and to what extent these differences explain differences in child growth. A previous investigation into households in these communities found household characteristics as independent variables explained only some variation in child growth (Spencer et al. 2017). We, therefore, examined the socioecological differences in the two communities using PCA - one PCA clustering household composition variables and another combining resource variables (agricultural-related variables and income access) - and relate these to the growth outcomes of children. Using a natural experimental design, we ask what (if any) characteristics of households' subsistence resources and household composition differ across communities and if and how this is related to child growth.

\section{Methods}

Spencer et al. (2018b) collected data from interviews in the post-rainy season of 2016 with householders in two rural communities, Ossu ( $n=96$ households) and Natarbora ( $n=94$ households), Timor-Leste. Interviews ascertained household demographics and resource availability (for details, see Reghupathy et al. 2012). The resources cataloged included forms of income (e.g., salaries, pensions, social support, and day-wages) and agricultural practices of the household (number of crops, and the number and type of animals). Dietary diversity and food variety scores (FVS) were calculated from 24-h food recalls (Ruel 2003; Styne et al. 2006), and FVS and frequency of egg consumption were included in this analysis. The numbers of resident grandparents / other adults, children (fostered and biological), and their relationships to the head woman of the household (or her husband) were recorded.

Anthropometric measures (height, weight, and middle-upper arm circumference) were recorded for all children to age 19 years and for mothers of those children when present. Height, weight, and body mass index (BMI) were standardized using the WHO protocol (de Onis et al. 2004). A total of 737 children aged from 1 month to 19 years were initially included in this analysis (mean $=9.6$ years of age, $\mathrm{SD}=5.15$ ). Children with any missing value were excluded from the linear mixed modeling of growth parameters.

Correlated characteristics of agricultural practice and income sources and household membership were aggregated using data from 192 households in two separate PCAs to reveal independent sets of correlated practices for each of the two themed sets of data. Food variety (FVS) was included in the agricultural practices PCA as dietary diversity scores showed insufficient variation among households. For each PCA, components were retained based on the percentage of variance explained and scree plot inspection and were subject to varimax rotation. We considered loadings of 0.35 and above in interpreting the component.

Relationships between the household composition conditions and the resource configurations were assessed by looking at the bivariate correlations of factor scores in households over the two sets of variables. 
To compare the principal components across the two communities, the factor scores obtained from each component of each PCA for households were compared across communities using an independent T-test for comparison of means. Those principal components were subsequently compared for effects on the growth of children in each community.

This research received ethics clearance and permission from the Ministry of Health, Timor-Leste (MS-INS/GDE/DP-EA/V/2016), and The University of Western Australia Human Research Ethics Committee (RA/4/1/2401).

\section{Results}

\subsection{Descriptives}

The descriptive characteristics of the two communities are detailed in Table 1. Ossu households tend to have more children per adult in the household, and are somewhat more are engaged in garden production. The vast majority of households in both communities raise livestock, but the species raised differ substantially; fifty percent more of the households in Natarbora raise cattle or water buffalo than Ossu households do. Natarbora also has many more households receiving veterans' pensions, which exceed in value all the other pensions.

Table 1. Number or percentage of households in Natarbora and Ossu engaged in agricultural activities and off-farm cash income in 2016.

\begin{tabular}{lcc}
\hline \multicolumn{1}{c}{ Variable Categories } & Natarbora & Ossu \\
\hline Households surveyed & 94 & 96 \\
Mean number of adults per household & 3.1 & 2.8 \\
Mean number of children per household & 3.9 & 4.1 \\
\% Making garden & 66.0 & 78.1 \\
\% Raising animals & 95.7 & 96.9 \\
\% Raising cattle and/or buffalo & 65.2 & 42.1 \\
\% Raising pigs & 83.0 & 85.4 \\
\% Raising chickens & 85.1 & 91.7 \\
\% With salary income & 27.7 & 30.2 \\
\% With pension income & 77.7 & 43.8 \\
\hline
\end{tabular}

\subsection{Family Composition and Resource Clusters}

The household composition PCA returned three independent components that, together, explain $72 \%$ of the variance in the co-resident household members. The first component loads most heavily on resident grandparents (both grandmothers and grandfathers) and has the only positive loading on fostered-in children (Table 2); this principal component itself explains $32.8 \%$ of the variance. The second component loads most heavily on numbers of adults (who are not grandparents) and numbers of children-indicating large two-generation households. The third component loads most heavily on children fostered out and on negative children fostered in-indicating smaller households that include only biological children (Table 2). 
Table 2. Variable loading for household composition (HC) principal component analysis (from Spencer et al. 2018b). Bolded indicates strong loadings $(\geq 0.35)$.

\begin{tabular}{cccc}
\hline Variable & $\begin{array}{c}\text { HC 1 } \\
\text { “Foster-in + } \\
\text { Grandparents" }\end{array}$ & $\begin{array}{c}\text { HC 2 } \\
\text { “Large 2 Generation } \\
\text { Households" }\end{array}$ & $\begin{array}{c}\text { HC 3 } \\
\text { "Foster-out, No } \\
\text { Grandparents, Few Adults” }\end{array}$ \\
\hline grandfather present & $\mathbf{0 . 9 2}$ & 0.02 & 0.01 \\
grandmother present & $\mathbf{0 . 9 1}$ & -0.07 & -0.07 \\
\# adults (excluding grandparents) & -0.02 & $\mathbf{0 . 8 0}$ & -0.19 \\
\# biological children & -0.02 & $\mathbf{0 . 7 6}$ & 0.33 \\
\# children fostered out & 0.08 & -0.08 & $\mathbf{0 . 8 4}$ \\
\# children fostered in & $\mathbf{0 . 3 5}$ & -0.33 & $-\mathbf{0 . 5 7}$ \\
\% Variance explained & 32.76 & 22.28 & 17.00 \\
\hline
\end{tabular}

The resources PCA yields four principal components that, together, explain $55.62 \%$ of the variance (Table 3). The first component we label "diverse subsistence" as it captures the production of small animals, crops, and a lack of cash income. The first component explains $17.6 \%$ of the variance and is closely followed by the second component that explains $16.4 \%$ of the variance. The second component indicates a reliance on salaried work and a lack of household food production. Disposable wealth is also indicated by the larger number of appliances in households with this subsistence strategy. The third component is dominated by high-value pensions and a larger number of pensions ( $11.9 \%$ of variance); pensions indicate income that does not require labor and thus lower trade-offs with other subsistence strategies. The last component ("large animal husbandry") is dominated by the raising of cows and pigs and income from agricultural sources ( $9.7 \%$ of variance).

Table 3. Variable loading for resources (Res) principal component analysis. Bolded indicates strong loadings ( $\geq 0.35)$.

\begin{tabular}{|c|c|c|c|c|}
\hline Variable & $\begin{array}{c}\text { Res } 1 \\
\text { "Diverse } \\
\text { Subsistence" }\end{array}$ & $\begin{array}{c}\text { Res } 2 \\
\text { "Salaries + } \\
\text { Appliances" }\end{array}$ & $\begin{array}{c}\text { Res } 3 \\
\text { "High Value } \\
\text { Pensions" }\end{array}$ & $\begin{array}{c}\text { Res } 4 \\
\text { “Large Animal } \\
\text { Husbandry" }\end{array}$ \\
\hline \#cows & 0.15 & -0.04 & 0.17 & 0.68 \\
\hline \#pigs & 0.16 & 0.11 & 0.34 & 0.61 \\
\hline \#chickens & 0.68 & 0.09 & 0.07 & 0.06 \\
\hline frequency eat eggs & 0.68 & 0.07 & -0.01 & -0.03 \\
\hline Food Variety Score & 0.66 & 0.04 & -0.01 & 0.11 \\
\hline \# crops grown & 0.37 & -0.66 & -0.01 & 0.16 \\
\hline Salary income & 0.23 & 0.61 & -0.17 & -0.08 \\
\hline High $\$ \$$ pensions & -0.14 & 0.10 & 0.82 & 0.17 \\
\hline Total \# pensions & 0.02 & -0.32 & 0.74 & 0.02 \\
\hline Agricultural income & -0.10 & -0.12 & -0.29 & 0.71 \\
\hline \# appliances & 0.27 & 0.76 & 0.03 & 0.14 \\
\hline$\%$ Variance explained & 17.61 & 16.41 & 11.90 & 9.70 \\
\hline
\end{tabular}

\subsection{Relationships of Family Composition and Resource Strategies}

To determine if there is a relationship between family composition and resource strategy, we performed a simple bivariate correlation of family composition and resource components (Table 4). Household composition best characterized as "grandparents and fostered-in children" was positively correlated with the PCA component "high-value pensions" (as might be expected given that veteran's pensions were more common for older men and some older women) and on resource strategies that focus on large animal husbandry and income from farm products. Households characterized by higher numbers of adult members other than grandparents and larger numbers of biological children were positively correlated with subsistence farming with little animal production, and there was a trend for association with large animal husbandry. Lastly, small families who had fostered 
children out of the household were negatively associated with all resource strategies-and the negative association with subsistence farming was significant.

Table 4. Correlational matrix of components of the resource PCA and the family composition PCA. Pearson's r, and $p$-value. $n=185$ households.

\begin{tabular}{|c|c|c|c|}
\hline & $\begin{array}{l}\text { HC } 1 \text { “Foster-in + } \\
\text { Grandparents" }\end{array}$ & $\begin{array}{c}\text { HC } 2 \text { "Large } 2 \text { Generation } \\
\text { Households" }\end{array}$ & $\begin{array}{c}\text { HC } 3 \text { “Foster-out, No } \\
\text { Grandparents, Few Adults" }\end{array}$ \\
\hline Res 1 “Diverse subsistence" & $\begin{array}{c}0.060 \\
p=0.408\end{array}$ & $\begin{array}{c}0.156 \\
p=0.034\end{array}$ & $\begin{array}{c}-0.184 \\
p=0.012\end{array}$ \\
\hline Res 2 "Salaries + appliances" & $\begin{array}{c}0.099 \\
p=0.181\end{array}$ & $\begin{array}{c}0.068 \\
p=0.360\end{array}$ & $\begin{array}{c}-0.048 \\
p=0.513\end{array}$ \\
\hline Res 3 "High value pensions" & $\begin{array}{c}0.368 \\
p<0.001\end{array}$ & $\begin{array}{c}-0.111 \\
p=0.134\end{array}$ & $\begin{array}{c}-0.055 \\
p=0.461\end{array}$ \\
\hline $\begin{array}{c}\text { Res } 4 \text { "Large animal } \\
\text { husbandry" }\end{array}$ & $\begin{array}{c}0.246 \\
p=0.001\end{array}$ & $\begin{array}{c}0.137 \\
p=0.063\end{array}$ & $\begin{array}{c}-0.067 \\
p=0.367\end{array}$ \\
\hline
\end{tabular}

\subsection{Comparing Household Composition and Resource Strategies in Ossu and Natarbora}

For the most part, the communities evidenced similar resource and family composition. However, one family composition component and two resource components differed significantly between the two communities (Table 5). Natarbora households had higher scores on high-value pensions (age and veteran's pensions) than Ossu households. Natarbora households also had higher factor scores on the large animal husbandry (pigs and cows) component than Ossu households. Lastly, Natarbora households had higher scores on the component of family structure that included multiple generations (presence of grandparents) as well as fostered-in children than Ossu households.

Table 5. Independent samples $t$-tests comparing household factor scores by subdistrict. Significantly different factors are bolded.

\begin{tabular}{|c|c|c|c|c|c|c|c|}
\hline Component & Subdistrict & $n$ & Mean & SD & $\mathbf{t}$ & df & $p$ \\
\hline \multirow{2}{*}{ Foster-in + grandparents } & Ossu & 96 & -0.16529 & 0.90359 & \multirow[t]{2}{*}{-2.325} & \multirow[t]{2}{*}{181.664} & \multirow[t]{2}{*}{0.021} \\
\hline & Natarbora & 94 & 0.16880 & 1.06828 & & & \\
\hline \multirow{2}{*}{$\begin{array}{c}\text { Large } 2 \text { generation } \\
\text { households }\end{array}$} & Ossu & 96 & 0.01598 & 1.18670 & \multirow[t]{2}{*}{0.223} & \multirow[t]{2}{*}{163.42} & \multirow[t]{2}{*}{0.824} \\
\hline & Natarbora & 94 & -0.01632 & 0.77017 & & & \\
\hline \multirow{2}{*}{$\begin{array}{l}\text { Foster-out, no grandparents, } \\
\text { few adults }\end{array}$} & Ossu & 96 & -0.08825 & 0.99131 & \multirow[t]{2}{*}{-1.231} & \multirow[t]{2}{*}{188} & \multirow[t]{2}{*}{0.220} \\
\hline & Natarbora & 94 & 0.09013 & 1.00607 & & & \\
\hline \multirow{2}{*}{ Diverse subsistence } & Ossu & 94 & 0.04299 & 0.99093 & \multirow[t]{2}{*}{0.593} & \multirow[t]{2}{*}{183} & \multirow[t]{2}{*}{0.554} \\
\hline & Natarbora & 91 & -0.04440 & 1.01284 & & & \\
\hline \multirow{2}{*}{ Salaries + appliances } & Ossu & 94 & -0.10599 & 0.92381 & \multirow{2}{*}{-1.470} & \multirow[t]{2}{*}{183} & \multirow[t]{2}{*}{0.143} \\
\hline & Natarbora & 91 & 0.10945 & 1.06711 & & & \\
\hline \multirow{2}{*}{ High value pensions } & Ossu & 94 & -0.36296 & 0.91110 & \multirow{2}{*}{-5.386} & \multirow[t]{2}{*}{183} & \multirow[t]{2}{*}{$<0.001$} \\
\hline & Natarbora & 91 & 0.37492 & 0.95234 & & & \\
\hline \multirow{2}{*}{ Large animal husbandry } & Ossu & 94 & -0.15957 & 0.86528 & \multirow{2}{*}{-2.230} & \multirow[t]{2}{*}{183} & \multirow[t]{2}{*}{0.027} \\
\hline & Natarbora & 91 & 0.16483 & 1.10304 & & & \\
\hline
\end{tabular}

3.5. Relationships of Community, Household Composition and Resource Strategies to Achieved Child Growth

To explore whether differences in practices between communities explain differences in child growth between communities, we ran linear mixed models for standardized height and for standardized BMI incorporating subdistrict, factor scores of three household composition components, and for the four resource strategy components. The inclusion of subdistrict in models despite known differences in resources between the two communi- 
ties allows the capture of latent variables not captured elsewhere, for example, familial affiliation. Resources may mediate the relationship between household composition and growth, or vice versa; however, the directionality of such relationships is unknown, and households maintain flexibility of both composition and resources. Household composition and resource variables were therefore included in the same rather than separate models to facilitate interpretation of results. A full model was reduced stepwise by removing the variable with the lowest significance (greatest $p$-value) and examining the Akaike AIC for efficiency of the model until reaching a minimum AIC and including all significant independent variables. Mother's height and child's sex were included due to known associations with child growth in this population.

Children's standardized height was predicted by the sex of the child and the mother's height, as was reported consistently for this population. While some of the resource strategies and household compositions were not related to child z-height (Table 6), the subdistrict was significant even when all resource strategies and household compositions were included. The community remained significant in the final model (Table 7). Thus, there are some differences between the communities in child height that are not captured by resource strategy or by household structure. Community is not merely a proxy for variations in socioecological practices.

Table 6. Initial LMM of $z$-height $(n=570$; AIC $=1556.036)$; reference category is in brackets. Significant predictors are bolded.

\begin{tabular}{|c|c|c|c|c|c|}
\hline Parameter & & Estimate & Std. Error & $\mathbf{t}$ & Sig. \\
\hline Intercept & & -10.423359 & 1.456631 & -7.156 & $<0.001$ \\
\hline Subdistrict & $\begin{array}{c}\text { Ossu } \\
\text { (Natarbora) }\end{array}$ & $\begin{array}{c}-0.421111 \\
0\end{array}$ & $\begin{array}{c}0.111504 \\
0\end{array}$ & -3.777 & $<0.001$ \\
\hline Sex of child & $\begin{array}{l}\text { Female } \\
\text { (Male) }\end{array}$ & $\begin{array}{c}0.217472 \\
0\end{array}$ & $\begin{array}{c}0.075936 \\
0\end{array}$ & 2.864 & 0.004 \\
\hline Mother's height in $\mathrm{cm}$ & & 0.057361 & 0.009552 & 6.005 & $<0.001$ \\
\hline Diverse subsistence & & -0.040200 & 0.049921 & -0.805 & 0.422 \\
\hline Salary + appliances & & 0.115425 & 0.047928 & 2.408 & 0.017 \\
\hline High-value pensions & & 0.074295 & 0.054813 & 1.355 & 0.177 \\
\hline Large animal husbandry & & -0.002299 & 0.053968 & -0.043 & 0.966 \\
\hline Foster in + grandparents & & -0.057679 & 0.056527 & -1.020 & 0.309 \\
\hline Large 2 generation households & & -0.190549 & 0.061204 & -3.113 & 0.002 \\
\hline Foster out, no grandparents, few adults & & -0.054851 & 0.053257 & -1.030 & 0.305 \\
\hline
\end{tabular}

Table 7. Final LMM of $z$-height $(n=564$; original AIC $=1582.549$, final AIC $=1570.147)$.

\begin{tabular}{ccccc}
\hline Parameter & & Estimate & EMM (SE) & $p$ \\
Intercept & & $-9.903(1.208)$ & & $<0.001$ \\
Subdistrict & Ossu & $0.479(0.083)$ & $-2.205(0.056)$ & $<\mathbf{0 . 0 0 1}$ \\
Sex of child & (Natarbora) & & $-1.726(0.059)$ & $\mathbf{0 . 0 0 6}$ \\
Mother's height (cm) & Female & $0.218(0.079)$ & $-1.857(0.056)$ & $<\mathbf{0 . 0 0 1}$ \\
Salaries + appliances & & $0.054(0.008)$ & & $\mathbf{0 . 0 1 0}$ \\
Large 2 generation households & & $0.100(0.039)$ & & $<\mathbf{0 . 0 0 1}$ \\
\hline
\end{tabular}

The relationship of z-BMI to socioecology and community was less straightforward. The starting model included all of the variables included in the height model noted above (Table 8). However, in the early steps of the refining process, the subdistrict was not a significant predictor of child z-BMI. In fact, only after all four resource components and one of the household composition variables were removed, a significance of less than 0.1 for community appeared (Table 9). Thus, there are community differences in these resource and household composition variables, but they are small in terms of their relationship to 
standardized BMI. The enduring socioecological variable that independently predicted z-BMI was the "grandparents and fostered-in children" household structure. Across communities, this is an independent predictor of better child z-BMI. "Grandparents and fostered-in children" households did not show better stature measures, so the positive association with z-BMI is more likely due to differences in weight for age.

Table 8. Initial LMM of z-BMI $(n=566$; AIC = 1701.415); reference category is in brackets. Significant predictors are bolded.

\begin{tabular}{|c|c|c|c|c|c|}
\hline Parameter & & Estimate & Std. Error & $\mathbf{t}$ & Sig. \\
\hline Intercept & & 0.797914 & 1.367643 & 0.583 & 0.560 \\
\hline \multirow{2}{*}{ Subdistrict } & Ossu & 0.143176 & 0.103004 & 1.390 & 0.165 \\
\hline & (Natarbora) & 0 & 0 & & \\
\hline Sex of the child & $\begin{array}{c}\text { Female } \\
\text { (Male) }\end{array}$ & $\begin{array}{c}0.243922 \\
0\end{array}$ & $\begin{array}{c}0.087900 \\
0\end{array}$ & 2.775 & 0.006 \\
\hline Mother's height in $\mathrm{cm}$ & & -0.013764 & 0.008962 & -1.536 & 0.125 \\
\hline More and higher value pensions & & -0.028407 & 0.050041 & -0.568 & 0.570 \\
\hline Salaries and appliances & & -0.014081 & 0.043770 & -0.322 & 0.748 \\
\hline More adults and morebiological children & & 0.089140 & 0.055626 & 1.602 & 0.110 \\
\hline Subsistence farming & & 0.008732 & 0.046232 & 0.189 & 0.850 \\
\hline Large animal husbandry & & 0.009824 & 0.050609 & 0.194 & 0.846 \\
\hline Foster in + grandparents & & 0.144478 & 0.052057 & 2.775 & 0.006 \\
\hline No fostering out; smallerfamilies & & -0.011883 & 0.049888 & -0.238 & 0.812 \\
\hline
\end{tabular}

Table 9. Final LMM of z-BMI $(n=566$; original AIC $=1701.415$, final AIC $=1673.785)$.

\begin{tabular}{ccccc}
\hline Parameter & & Estimate & EMM (SE) & $p$ \\
\hline Intercept & & $-1.296(0.078)$ & & $<0.001$ \\
Subdistrict & Ossu & $0.228(0.089)$ & $-0.945(0.061)$ & $-1.173(0.064)$ \\
Sex of child & (Natarbora) & & $-0.929(0.062)$ & $\mathbf{0 . 0 1 1}$ \\
"Foster in + grandparents" & Female & $0.261(0.087)$ & $-1.190(0.061)$ & $\mathbf{0 . 0 0 3}$ \\
\hline
\end{tabular}

\section{Discussion}

\subsection{Relationships of Family Composition and Resource Strategy}

The family composition in the two communities related to both resident numbers and generational relationships. In both communities, stem families (grandparent(s), parents, and children) were common. In both communities, the presence of three generations explained more of the structural variation-where grandparents were present, fostered-in children were more likely. The second form of family structure included more adults, but more often only two generations-including collateral relatives of the wife and/or husband in the household (joint families). Lastly, the third type of family is more characterized by who is not present-children have been fostered out of the family, and there are fewer adults. The family composition was related to resource strategies. Three-generational families were significantly more likely to have high-value pensions and to raise large animals-which in Timor-Leste often serve more like a local "bank account" than as a food source. Cows are sold on the hoof to finance large expenses (school fees, medical procedures) or purchases. High-value pensions and large animal husbandry were in different components and suggested two independent resource strategies rather than the use of pensions to acquire livestock. Larger two-generational families were more likely to engage in subsistence agriculture with less access to cash, whereas the smaller families of the third type were significantly less likely to engage in agriculture and were not associated with any particular type of resource access. The causal direction of such relationships cannot be determined from cross-sectional data; however, we can infer some causality to resource access given that the families with the least resources more often 
fostered children out and the families with loadings on both high-value pensions and on large animal husbandry were more likely to have fostered children in. This is clearly a recursive relationship; however, large animals require people to tend them, and families are unlikely to foster in children unless they have the resource wherewithal to do so-children cannot produce either pensions or livestock. Notably, the PCA for family composition explained $72 \%$ of the variance in composition variables, while the resource PCs explained only $56 \%$ of the variance overall. The economic environment in rural Timor-Leste is developing albeit slowly, and most strategies for earning income are limited and precarious. While grandparents may increase the likelihood of pensions (age pensions and veterans pensions), it is likely that these household resources attract children from related families who are fostered-in where resources allow. We know from other contexts (e.g., Akresh 2009) that families tend to send children to higher-quality households within their network. It would be interesting to examine whether the families that load highly on the fostering-out and low resource components are sending their children to families that link highly on higher resource components and three-generational households. We are unable to perform this with the data at hand.

Families with more adults in residence and only their own biological children are associated with subsistence farming and a positive correlational trend toward large animal husbandry (Table 4). Thus, families augmented through fosterage or through co-residence with grandparents are likely to have some wealth either in cash or in herds of animals. Most salaries are the result of education, and thus, as would be expected, there is no relationship between salary income and family composition. Families not involved in salaried employment, in subsistence farming, or in large animal husbandry have the fewest members and the least complex family structure.

\subsection{Differences in Strategies between Communities and Child Growth}

Given the difference in family strategies and their relationships to resource acquisition strategies, it is important to consider whether various household compositions and strategies can be related to child growth. With a persistent problem of poor child growth in rural Timor-Leste and with various resource strategies, such an analysis may allow fine-tuning of development and aid strategies meant to address both economic development and human well-being.

Standardized height is an indicator of long-term growth. While poor conditions cannot cause stature to decline, it can result in achieved stature that is low for age (Black et al. 2013). Notably, only families with dependable access to cash income (salaries) had children who were significantly taller than their peers (Table 7), and families with larger numbers of adults and who engage in subsistence agriculture had children significantly shorter for age and sex. The children in three-generation families with both livestock and pensions did not show improved growth, perhaps because family size increases through fostering as resources increase. In addition to these contemporary influences, standardized height is strongly related to maternal height and shows an independent community effect even after resource strategies and family composition are considered. Spencer et al. (2018b) suggest that historically better conditions in Natarbora may express as greater maternal stature with epigenetic effects on their children's heights for age and sex relative to children in Ossu (work on this hypothesis is ongoing). Weight for sex and age is a better index of short-term nutrition as it can fluctuate more widely and as storing nutrients is requisite for linear growth to occur. Standardized body mass index is a problematic index of growth because it is a composite of stature and weight-poor growth in stature can present as good body mass index; however, WHO standardized values for weight end after 10 years of age. We look at standardized body mass index in order to include children throughout their developmental period.

The relationships of family structure, resource acquisition, and community of residence are complex. In the full model (Table 9), the only principal component that shows a significant independent effect on body mass index is living in a household with grandpar- 
ents and fostered-in children. There was no community effect, and none of the resource strategies had significant influence. The lack of community effect may have to do with the community difference in height. Ossu children with poor stature may be artificially inflated in their BMI measure due to the manner in which BMI is calculated, and thus hide a community effect on weight. However, as resource variables were removed in the stepwise process, the community effect increased. When all of the resource components were excised, the community estimate increased from $0.143(p=0.165)$ to $0.167(p=0.074)$; the increase in parameter estimate increased until, in the final model, it was 0.228 ( $p=$ 0.011). This suggests that some of the persistent community effects in children's growth relate to differences in the resource strategies employed by the households in which they live, but not all.

Overall, three socioecological elements present may buffer children against poor growth-grandparents present, receiving income (salaries or larger pensions), and having more animals. Households with grandparents, households with high-value pensions, and households raising large animals are more evident in Natarbora. Furthermore, mothers are taller in Natarbora, suggesting that there is an intergenerational continuance of these differences. The interrelationships between family configurations and strategies linked to better growth suggest that nuanced and diverse resource development programs are likely to be necessary over longer periods of time to result in improved growth and well-being in rural Timorese children. If increased predictability and levels of resources attract child fosterage, then improvements in those resources may increase the number of children exposed to better conditions but be less quantifiable on a per children basis. Evaluations of aid programs may find more children showing only slightly better anthropometric indicators rather than larger changes in growth. This may explain why we find some family composition effects but few resource effects on growth. Children fostered into households with more (post-reproductive) grandparents reduce the benefit of improved resources to biological children in those households while also reducing the number of children in their natal households who share the lower levels of precarious resources. The social practice of child mobility buffers the effect of varying resource strategies on children.

Author Contributions: Conceptualization, D.S.J.; Formal analysis, P.R.S. and D.S.J.; Funding acquisition, D.S.J.; Investigation, P.R.S.; Methodology, P.R.S. and D.S.J.; Project administration, D.S.J.; Writing-Original draft, D.S.J.; Writing-Rreview \& editing, P.R.S. All authors have read and agreed to the published version of the manuscript.

Funding: This research was funded by the Australian Research Council (DP 120101588 to Debra Judge et al.), and by the School of Human Sciences, University of Western Australia.

Institutional Review Board Statement: Human Ethics approval was granted by the University of Western Australia (RA/4/1/2401) and the Ministry of Health, Timor-Leste.

Informed Consent Statement: Informed consent was obtained from all subjects involved in the study.

Data Availability Statement: Data available upon request.

Conflicts of Interest: The authors declare no conflict of interest.

\section{References}

Akresh, Richard. 2009. Flexibility of household structure child fostering decisions in Burkina Faso. Journal of Human Resources 44: 976-97. [CrossRef]

Bettencourt, Elisa Maria Varela, Mario Tilman, Pedro Damião de Sousa Henriques, Narciso Vanda, and Maria Leonor da Silva Carvalho. 2013. The Economic and Sociocultural Role of Livestock in the Wellbeing of Rural Communities of Timor-Leste. Congresso da Sociedade Brasileira de Economia, Administracao e Sociologia Rural. Available online: http://hdl.handle.net/10174/9347 (accessed on 9 July 2021).

Black, Robert E., Cesar G. Victora, Susan P. Walker, Zulfiqar A. Bhutta, Parul Christian, Mercedes de Onis, Majid Ezzati, Sally Grantham-McGregor, Joanne Katz, Reynaldo Martorell, and et al. 2013. Maternal and child undernutrition and overweight in low-income and middle-income countries. The Lancet 382: 427-51. [CrossRef] 
Chen, Lincoln C., Emdadul Huq, and Stan D'Souza. 1981. Sex bias in the family allocation of food and health care in rural Bangladesh. Population and Development Review 7: 55-70. [CrossRef]

Crooks, Deborah L., Lisa Cliggett, and Steven M. Cole. 2007. Child growth as a measure of livelihood security: The case of the Gwembe Tonga. American Journal of Human Biology 19: 669-75. [CrossRef] [PubMed]

de Onis, Mercedes, Adelheid W. Onyango, Jan Van den Broek, Wm. Cameron Chumlea, and Reynaldo Martorell. 2004. Measurement and standardization protocols for anthropometry used in the construction of a new international growth reference. Food and Nutrition Bulletin 25: 27-36.

Goody, Jack. 1976. Production and Reproduction: A Comparative Study of the Domestic Domain. Cambridge: Cambridge University Press.

Hadley, Craig. 2004. The cost and benefits of kin: Kin networks and children's health among the Pimbwe of Tanzania. Human Nature 15: 377-95. [CrossRef] [PubMed]

Harrison, Geoffrey A., and Lincoln H. Schmitt. 1989. Variability in stature growth. Annals of Human Biology 16: 45-51. [CrossRef] [PubMed]

Judge, Debra S., Katherine A. Sanders, Nadine Reghupathy, Pedro Canisio Amaral, and Lincoln H. Schmitt. 2012. Family Influences on Long-term and Short-term Child Growth in Ossu Area, Timor-Leste. In New Research on Timor Leste. Melbourne: Swinburne Press, pp. 233-41.

Macrotrends. 2020. Timor-Leste Rural Population 1960-2021. Available online: https:/ /www.macrotrends.net/countries/TLS/timorleste/rural-population (accessed on 9 July 2021).

Narciso, Vanda, Pedro Damião de Sousa Henriques, and Mario Tilman. 2012. Land and Gender in Matrilineal Timor-Leste. Repositorio Universidade de Evora. Available online: http:/ /hdl.handle.net/10174/7097 (accessed on 9 July 2021).

Reghupathy, Nadine, Debra S. Judge, Katherine A. Sanders, Pedro Canisio Amaral, and Lincoln H. Schmitt. 2012. Child size and household characteristics in rural Timor-Leste. American Journal of Human Biology 24: 35-41. [CrossRef] [PubMed]

Ruel, Marie T. 2003. Is dietary diversity an indicator of food security or dietary quality? A review of measurement issues and research needs. Food and Nutrition Bulletin 24: 231-232. [CrossRef]

Spencer, Phoebe R., Katherine A. Sanders, Pedro Canisio Amaral, and Debra S. Judge. 2017. Household resources and seasonal patterns of child growth in rural Timor-Leste. American Journal of Human Biology 92: e22916. [CrossRef]

Spencer, Phoebe R., Katherine A. Sanders, and Debra S. Judge. 2018a. Growth curves and the international standard: How children's growth reflects challenging conditions in rural Timor-Leste. American Journal of Physical Anthropology 165: 286-98. [CrossRef]

Spencer, Phoebe R., Katherine A. Sanders, and Debra S. Judge. 2018b. Rural Livelihood Variation and its Effects on Child Growth in Timor-Leste. Human Ecology 46: 1-13. [CrossRef]

Spencer, Phoebe R., Katherine A. Sanders, and Debra S. Judge. 2019. Determinants of objectively measured physical activity in rural East Timorese children. American Journal of Human Biology 31: e23247. [CrossRef]

Styne, Nelia P., Johanna Nel, Guy Nantel, Gina Kennedy, and Demetre Labadarios. 2006. Food variety and dietary diversity scores in children: Are they good indicators of dietary adequacy? Public Health Nutrition 9: 644-50. [CrossRef]

Thu, Pyone Myat, and Debra S. Judge. 2017. Household agricultural activities and child growth: Evidence from rural Timor-Leste. Geographical Research 55: 144-55. [CrossRef]

United Nations Development Programme. 2020. Human Development Report 2020: Timor-Leste. Available online: http:/ hdr.undp. org/sites/default/files/Country-Profiles/TLS.pdf (accessed on 9 July 2021). 